\title{
Validation of a Design Procedure for Failure Mode Control of EB-Frames: Push-Over and IDA Analyses
}

\author{
Luigi Mastrandrea, Elide Nastri and Vincenzo Piluso*
}

Department of Civil Engineering, University of Salerno, Italy

\begin{abstract}
The paper is devoted to the investigation of the seismic response of eccentrically braced frames characterised by links having different length. In addition, the analysed structures have been designed according to a methodology, already proposed by the authors, aiming to guarantee a collapse mechanism of global type. Therefore, the results of the nonlinear analyses herein presented provide the validation of the proposed design procedure, by testifying that all the designed structures exhibit a global failure mode where all the links are yielded while all the columns remain in elastic range with the exception of the base section of first storey columns, leading to high energy dissipation capacity and global ductility.

Furthermore, two different distributions of the link lengths are examined. The first one is characterised by short links with uniform lengths along the height of the structure. The second one is characterised by the use of link elements having different length at the different storeys which are selected to assure the same value of the non-dimensional link length.

The seismic response of EB-Frames with such distributions of the link length is investigated by means of both push-over analyses and dynamic non-linear analyses. The comparison of the performances is mainly carried out in terms of plastic hinges distribution, local ductility demand and frame lateral stiffness.
\end{abstract}

Keywords: Eccentrically braced frames, non-dimensional link length, collapse mechanism, push-over analysis, Incremental Dynamic Analysis, local ductility demands.

\section{INTRODUCTION}

It is well known that eccentrically braced frames (EBFs) constitute a suitable structural typology for both interstorey drift limitation and energy dissipation capacity. In fact, EBFs are characterised by adequate lateral stiffness, as required to satisfy the serviceability limit state requirements, and high global ductility, as required to assure collapse prevention under severe earthquakes.

The main parameter governing the seismic response of such structural typology, both in elastic and post-elastic range, is the length $e$ of the links, which constitute the dissipative zones. In fact, this parameter influences the lateral stiffness of the structure, the ability to dissipate the seismic input energy and the link plastic rotation demands.

In particular, the lateral stiffness of the bracing system increases as far as the link length decreases [1]. It is possible to recognise that eccentrically braced frames are very sensitive to the variation of the ratio between the link length and the bay span $e / L$, since, at least for $e / L<0.4$, a little decrease of this parameter is responsible of a significant increase in lateral stiffness. This effect is more and more important as far as $e / L$ decreases, and it is more evident in split- $K$ configurations (where two diagonal braces are connected at the ends of the link located at beam mid-span) rather than in $D$ ones (where there is only one brace element and the link is

\footnotetext{
*Address correspondence to this author at the Department of Civil Engineering, University of Salerno, Italy; Tel: +39 089 964108;

Fax: +39089 968731; Email: v.piluso@unisa.it
}

connected directly to the column). The limit case $e / L=0$ can be ideally associated to the case of concentrically braced frames providing the highest lateral stiffness, while, conversely, the case of $e / L=1$ is representative of moment resisting frames, providing the minimum lateral stiffness. Preliminary design equations for estimating the stiffness of EBFs have been recently proposed [2].

In addition, depending on the length $e$, the mechanical behaviour of links varies from pure shear to pure bending and it governs the cyclic response, i.e. the dissipative capacity of the structure. It is well known that, under this point of view, links are classified into three categories, namely short, intermediate and long links, depending on the ratio $M_{p} / V_{p}$ between the plastic moment and the plastic shear of the cross section [3-6]. The shear action is dominant for $e \leq 1.6 M_{p} / V_{p}$ (i.e. in case of short links), while the bending moment becomes more and more relevant as far as the link length $e$ increases, until it becomes dominant for $e \geq 3.0 M_{p} / V_{p}$ (i.e. in case of long links).

Due to their performance in terms of both stiffness and ductility, short links are in several cases the most suitable choice for seismic-resistant EBFs. In fact, the cyclic behaviour of short links is characterised by wide and stable cycles allowing the development of high energy dissipation capacity, provided that adequate web stiffeners are adopted along the element length to prevent web local buckling. In such a case, high rotation capacity has been experimentally exhibited by short links when compared to intermediate and long ones $[4,6,7]$. Several tests have clearly shown that a prop- 
erly stiffened short link can sustain plastic rotations up to \pm 0.09 rad under cyclic loading conditions or up to $0.20 \mathrm{rad}$ under monotonic loading conditions $[3,7]$. Despite of web stiffeners, shear buckling has been typically observed as the controlling failure mode, but the mechanism is delayed allowing the complete distribution of the inelastic shear strains over the whole length of the link.

Conversely, long links are characterised by a completely different failure mechanism where large flexural deformations lead to the fracture of tensile flanges or to the lateral torsional buckling of compressed ones. As a result, maximum plastic rotations up to \pm 0.02 rad have been experimentally measured [7]. Finally, intermediate links are characterised by a combination of the previously discussed effects, depending on the combination of shear force and bending moment.

From the design point of view, on one hand, it has to be considered that short links provide the highest plastic rotation supply, but also, on the other hand, the highest plastic rotation demand for a given lateral displacement; the opposite case occurs when long links are adopted, while intermediate links provide an intermediate behaviour. For this reason, care has to be taken in the selection of the link length, which governs the overall ultimate behaviour, the local ductility (both demand and supply) and the stiffness of the structure. Consequently, the main goal of the design process of an eccentrically braced frame is the identification of the best compromise between the need, on one hand, to develop high lateral stiffness and plastic rotation supply which increase as far as the link length decreases and, on the other hand, the need to reduce the plastic rotation demands which, conversely, decrease as far as the link length increases.

Within the framework of advanced design methodologies for seismic-resistant structures, based on the Theory of Plastic Mechanism Control (TPMC), the authors have already developed a design methodology for EBFs able to assure a collapse mechanism of global type under severe earthquakes $[8,9]$. In fact, the collapse mechanism control is universally recognised as one of the primary goals of the structural design process for seismic-resistant structures, aiming at the prevention of undesired collapse mechanism typologies

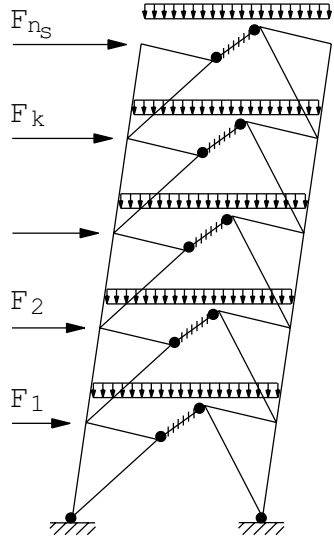

GLOBAL MECHANISM

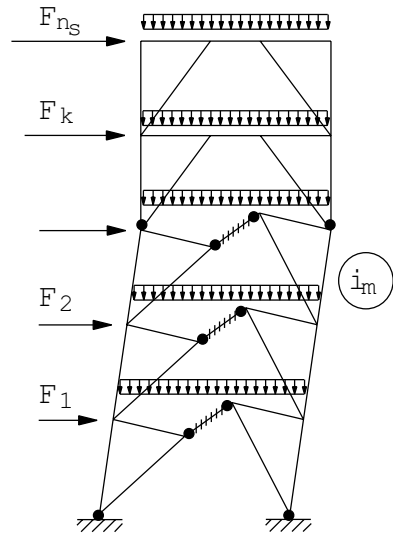

TYPE-1 MECHANISM

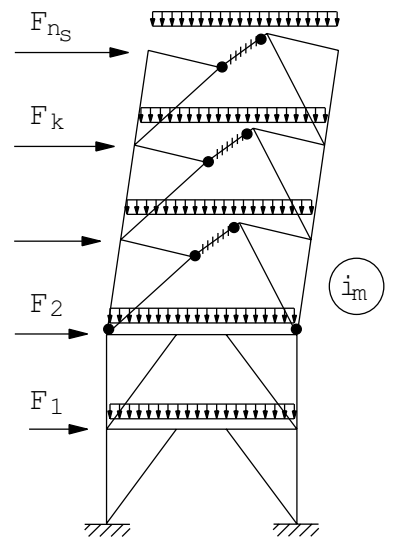

TYPE-2 MECHANISM which are not satisfactory in terms of energy dissipation capacity (see mechanism types $1 \div 3$ in Fig. 1). In particular, the best seismic performance of EB-Frames occurs by concentrating plastic deformations in the links, while columns, diagonals and beam parts outside of links have to remain in elastic range (with the only exception of base sections of first storey). To this scope, the author design methodology is based on the kinematic theorem of plastic collapse, which is applied to determine the design conditions to be satisfied to avoid all the undesired mechanisms. The design algorithm is based on the assumption that link sections are dimensioned to resist the design seismic horizontal forces, while column and diagonal sections constitute the problem unknowns. They are determined by applying the kinematic theorem of plastic collapse extended to the concept of mechanism equilibrium curve, so that also second order effects are accounted for $[8,9]$.

The accuracy of the design procedure has been already tested by means of static and dynamic non-linear analyses, which have been preliminarily carried out with reference to EBFs with short links having a fixed length equal to $70 \mathrm{~cm}$ $[8,10]$. In particular, the analyses have shown the involvement of all the dissipative zones in the collapse mechanism, leading to a very good global ductility for all the analysed cases. On the other hand, due to the geometrical configuration, short links also appeared to be affected by high local ductility demands. This circumstance could undermine the seismic performance of the structure, because could anticipate the collapse due to the exceedance of the local ductility supply.

With the aim to widely investigate this issue, in this work attention is focused on the influence of the link length on the seismic performance of EB-Frames designed to assure a collapse mechanism of global type. In particular, EBFs with short, intermediate and long links designed according to the author methodology $[8,9]$ are analysed. Furthermore, also an alternative approach is adopted in the selection of the link lengths. On the basis of the chosen post-elastic behaviour required for the member, link lengths are selected by means of the corresponding non-dimensional value, which will be defined in next Sections. As it will be clear, this procedure assures the maximum length compatible with the desired

Fig. (1). Collapse mechanisms for EBFs. 
ultimate behaviour of the link, reducing the expected local ductility demands. Different geometrical lengths of the links along the height of the structure are obtained.

The investigation of the seismic response of the designed structures is performed by means of both push-over and dynamic non-linear analyses. The primary aim of push-over analyses is the prediction the actual collapse mechanism to be compared with the design goal, i.e. the global mechanism. Dynamic analyses are devoted to establish the actual pattern of yielding of the structure under real earthquake actions, in order to judge the degree of accuracy with respect to the desired failure mode, i.e. the global one, and to evaluate the distribution of the local ductility demands.

In next Sections, after a very brief presentation of the above mentioned design methodology, the selection criterion for the link length will be explained and motivated. Then, the main results of non-linear analyses will be presented and discussed.

\section{PLASTIC DESIGN OF ECCENTRICALLY BRACED FRAMES}

Eccentrically braced frames herein examined are dimensioned according to a design methodology proposed by the authors in a recent work $[8,9]$. The approach has a general relevance, being independent of the geometrical scheme of EB-Frames (split- $K, D$ and inverted $Y$ configurations) and link ultimate behaviour (short, intermediate and long links), and it is briefly summarised in the following in order to allow a better comprehension of the presented results. In addition, the theory of plastic mechanism control (TPMC), based on the kinematic theorem of plastic collapse and its extension to the concept of mechanism equilibrium curve, has already been developed also in the case of MR-Frames [11, 12], MRF-EBF dual systems [13] (i.e. moment resisting frames-eccentrically braced frames dual systems), knee braced frames (KBFs) [14-16], which is a structural typology having several similarities to EBFs, as underlined in [16], and in case of Dissipative Truss Moment Frames (DTMFs) [17]. Conversely, a more simple approach directly based on the rigorous application of capacity design principles can be applied for the plastic mechanism control of concentrically braced frames $[18,19]$.

As previously clarified, the aim of the procedure is the design of eccentrically braced frames able to develop a global mechanism at collapse. The procedure is developed within the framework of rigid-plastic analysis, so that deformations occurring before the complete development of the kinematic mechanism are not considered. With reference to this issue, in order to calculate the involved virtual works needed to the design process, the link is modelled as an element with plastic hinges in simple bending by means of the equivalent ultimate moment concept $\left(M_{e q}\right)$ introduced by the same authors and calculated on the basis of the equivalence in terms of virtual internal work between the actual link and the simple bending model [20-22]. This tool takes into account the mechanical behaviour of the link (short, intermediate or long link according to the above described classification [3]) and allows to provide a unique formulation of the internal virtual work. In particular, with reference as an example to split- $K$ EBFs, on the basis of the moment-shear interaction diagram evaluated according to Neal [23] and by assuming a homothetic expansion of the plastic domain to account for strain-hardening effects, the following expressions for the equivalent ultimate moment have been provided [20]:

$$
\begin{aligned}
& M_{e q}^{\text {(short) }}=\frac{V_{u} e}{2} \\
& M_{e q}^{\text {(intermediate) }}=\frac{e}{2 L}\left(2 \beta M_{f u}+\sqrt{4\left(M_{u}-M_{f u}\right)^{2} \beta^{2}+V_{u}^{2}(L-\beta e)^{2}}\right) \\
& M_{e q}^{\text {(long) }}=M_{u}
\end{aligned}
$$

for short, intermediate and long links, respectively, while the internal virtual work corresponding to the plastic rotation $\gamma$ of the link assumes the classical format of the simple bending model:

$$
W_{i . l i n k}=2 M_{e q} \gamma
$$

In Eqs. (1)-(3) the symbols $V_{u}, M_{u}$ and $M_{f u}$ denote the ultimate shear resistance, the ultimate moment resistance and the contribution of the flanges to the ultimate moment of the section, respectively. The ultimate resistance is affected by strain-hardening effects, whose influence is usually accounted for by means of a 50\% increase of the plastic resistances $[24,25]$. Furthermore, the parameter $\beta$ is equal to [20]:

$$
\beta=\left(\frac{V_{u} e-\frac{4\left(M_{u}-M_{f u}\right) M_{f u}}{\sqrt{4 M_{u}\left(M_{u}-2 M_{f u}\right)+V_{u}^{2} e^{2}}}}{4\left(M_{u}-M_{f u}\right)^{2}+V_{u}^{2} e^{2}}\right) V_{u} L
$$

Starting from this issue, the design problem is solved under the assumption that link sections are known, since they are dimensioned on the basis of the internal actions coming from the seismic horizontal forces, while column and diagonal sections are the unknowns of the design problem. Design equations are determined on the basis of the kinematic theorem of plastic collapse. In particular, to account for second order effects, the upper bound theorem of limit analysis is applied with reference to the concept of mechanism equilibrium curve, which represents the linearization of the postmechanism branch of the behavioural curve $\alpha$ - $\delta$ (i.e. multiplier of horizontal forces versus top sway displacement curve) of the frame, whose slope is strongly influenced by the sensitivity to second order effects [11].

Therefore, the design conditions are defined by imposing that the mechanism equilibrium curve corresponding to global type mechanism has to be located below those corresponding to all the other undesired mechanisms for each displacement level, at least within a range compatible with the plastic deformation capacity of members. This condition guarantees that the admissible multiplier of horizontal forces corresponding to the global mechanism is the minimum among all the others undesired kinematic mechanisms within a displacement range compatible with the local ductility of dissipative zones. Therefore, according to limit design principles the global mechanism is assured within the design displacement range and, under this point of view, the design process assures also the local ductility control. 
The design procedure has been implemented into a computer program, namely SOPDEBF (Second Order Plastic Design of Eccentrically Braced Frames). The validation of the method has already been performed by means of pushover analyses, carried out by means of SAP2000 computer program [26], whose results confirmed the achievement of the global collapse mechanism in all the studied cases [10]. In addition, high energy dissipation capacity and high global ductility confirmed the good performance of eccentrically braced frames as seismic-resistant structures.

\section{NON-DIMENSIONAL LINK LENGTH}

As already underlined, both international codes and technical literature classify links of EBFs into three different typologies depending on the ultimate behaviour of the member. In fact, by progressively increasing the link length, the plastic behaviour of the link is dominated by pure shear (short links), by the interaction between shear force and bending moment (intermediate links) and, finally, by pure bending (long links). In particular, the classification is based on the following behavioural ranges [3]:

- short links for e $\leq 1.6 \mathrm{M}_{\mathrm{p}} / \mathrm{V}_{\mathrm{p}}$

- intermediate links for $1.6 \mathrm{M}_{\mathrm{p}} / \mathrm{V}_{\mathrm{p}}<\mathrm{e}<3 \mathrm{M}_{\mathrm{p}} / \mathrm{V}_{\mathrm{p}}$

- long links for $\mathrm{e} \geq 3 \mathrm{M}_{\mathrm{p}} / \mathrm{V}_{\mathrm{p}}$

being $e$ the link length, and $M_{p}$ and $V_{p}$ the plastic moment and the plastic shear of the cross section, respectively.

Starting from the previous classification, it is useful to define the following parameter:

$$
\bar{e}=\frac{V_{p} e}{M_{p}}
$$

which can be defined non-dimensional length of the link, depending on the mechanical characteristics of the cross section and geometry.

From an analytical point of view, it is easy to recognize that the ultimate behaviour of the link is strictly related to the parameter $\bar{e}$. In particular, the collapse of the member is more and more governed by the shear action as far as $\bar{e}$ decreases (assuring, however, $\bar{e} \leq 1.6$ ). Conversely, the ultimate behaviour is more and more governed by the bending moment as far as $\bar{e}$ increases (assuring the condition $\bar{e} \geq 3$ ).

From a physical point of view, it is useful to note that links characterised by the same value of $\bar{e}$, although characterised by different cross sections and different lengths, provide the same ultimate behaviour. Consequently, if an EBFrame is designed by imposing the same value of the nondimensional length for all the links, a uniform behaviour at collapse is expected.

On the other hand, since the design of the link section is governed by the seismic storey shear, the resulting section sizes decrease from the bottom storey to the top storey of the building. As, for usual standard shapes, the ratio $V_{p} / M_{p}$ decreases as far as the size of the cross section increases, it can be recognized that, in order to obtain a constant value of the parameter $\bar{e}$, the length of the link $e$ at bottom storey needs to be greater than the one of the link at the top storey. As a consequence, the link plastic rotation demands are not uniform along the building height, but they increase from the bottom storey to the top one (Fig. 2). Despite of this geometrical condition seems to lead to a premature collapse of the top storey link, because of the dynamic response, which will be discussed in next Sections, the energy dissipation capacity of such EB-Frames with constant non-dimensional link length ( $\bar{e}=$ constant) is close to that obtained in case of uniform link length $(e=$ constant).

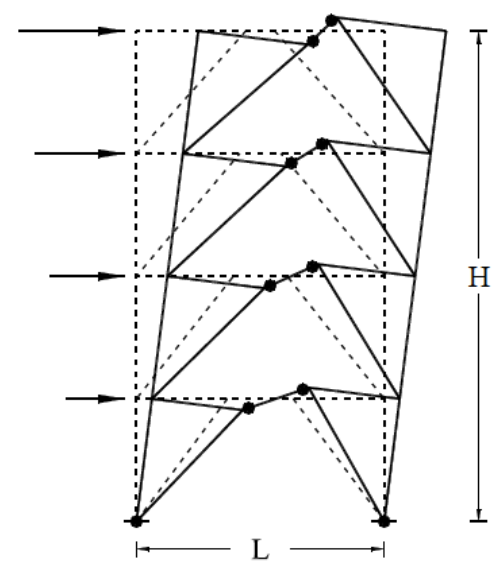

Fig. (2). Global mechanism of an EB-Frame with constant value of $\bar{e}$.

\section{APPLICATIONS}

In this paper, Eq. (6) is adopted as an alternative criterion for link design in EB-Frames. The criterion consists in designing EBFs by imposing a constant value of the parameter $\bar{e}$ along the height of the structure. In particular, in the following analyses, the values 1.6, 2.3 and 3.0 have been adopted to compare the seismic performance obtained for short, intermediate and long links, respectively.

Aiming at the limitation of local ductility demands, the value $\bar{e}=1.6$ (corresponding to the upper bound of the short link length range) has been chosen for short links. This choice guarantees a collapse behaviour in pure shear with the maximum allowable geometrical length for the member. Conversely, the value $\bar{e}=3.0$ (corresponding to the lower bound of the long link length range) has been chosen for long links aiming to guarantee a collapse in pure bending maximising the lateral stiffness of the structure. Finally, the value $\bar{e}=2.3$ (corresponding to the middle of the length range) has been chosen for intermediate links aiming to the investigation of the seismic response of EBFs in cases where moment-shear interaction is very important.

In addition, in order to compare the seismic response of eccentrically braced frames characterised by a uniform distribution of the non-dimensional link length along the building height with the one provided in case of constant geometrical link length, the analysed schemes have also been designed with reference to the case of $e=70 \mathrm{~cm}$ for each storey.

With reference to the above selected values of $\bar{e}$ and $e$, EBFs have been designed according to the rigorous procedure for failure mode control previously discussed [8]. All the designed frames are referred to the structural scheme 
depicted in (Fig. 3). The part of the structure outside of the EB-Frame is pinned at each beam-to-column connection and at the base of the columns, so that only the EB-Frame resists to the seismic horizontal forces, while the other parts are only able to carry vertical loads. The bay span is $L=6.0 \mathrm{~m}$ and the interstorey height is $h=3.0 \mathrm{~m}$, while the link lengths are variable as previously described. The characteristic values of the vertical loads of the analysed scheme are equal to $9 \mathrm{kN} / \mathrm{m}$ and $6 \mathrm{kN} / \mathrm{m}$ for permanent $\left(G_{k}\right)$ and live $\left(Q_{k}\right)$ loads, respectively. Consequently, in the seismic combination of actions $\Sigma G_{k}+\Sigma \psi_{2} Q_{k}+\gamma_{I} E_{d}$ (where $\psi_{2}$ is the coefficient for the quasi-permanent value of the variable actions, $\gamma_{I}$ is the importance factor and $E_{d}$ is the design value of the earthquake action), the uniform vertical load acting on the beams is $\left(\psi_{2}=0.3\right.$ for residential buildings):

$$
q=9+0.3 \times 6=10.8 \mathrm{kN} / \mathrm{m}
$$

The structural material adopted for all the members is S275 steel grade (nominal yield strength $f_{y}=275 \mathrm{MPa}$ ).

The design horizontal forces have been determined according to Eurocode 8, assuming a peak ground acceleration equal to $0.35 g$, a seismic response factor equal to 2.5 , a behaviour factor $q$ equal to 6 , and an importance factor $\gamma_{I}$ equal to 1.0 [10]. In addition, an horizontal force distribution according to the first vibration mode is assumed. Nevertheless, this assumption does not constitute a restriction to the method. In fact, the design methodology can be applied within an iterative approach, in which the triangular distribution can be useful as a first attempt for dimensioning the structure. Successively, by means of modal analysis, the distribution of the horizontal forces can be updated by means of a combination of the most relevant vibration modes, and the design approach can be applied again. However, according to the author experience the assumption of an horizontal force distribution according to the first vibration mode is accurate in case of structures designed aiming to the global failure mode, because also the shape of the vector of horizontal plastic displacements is triangular (Fig. 1).

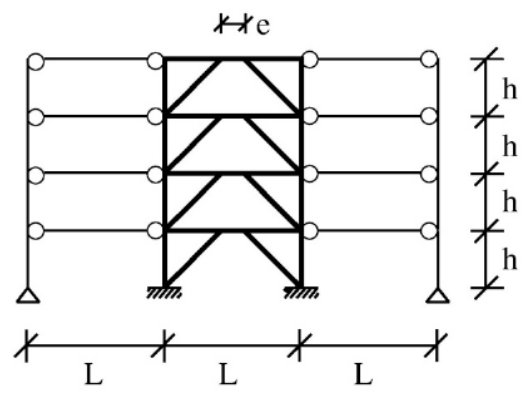

Fig. (3). EB-frame split-K scheme.

Notwithstanding, the performances of the designed structures have been tested by means of both push-over and dynamic non-linear analyses, as discussed in further Sections. Therefore, since dynamic non-linear analyses automatically account for the influence of all the vibration modes, the corresponding results provide the actual response of the structure, and they constitute a measure of the accuracy of the proposed procedure even when the design is carried out assuming an horizontal force distribution according to the first eigenmode.
In particular, EBFs with 2 to 12 storeys have been investigated. In Table 1, as an example, the seismic horizontal forces and the corresponding storey shears are reported with reference to the 8-storey EB-Frame.

Table 1. Design Seismic Forces for the 8-Storey EB-Frame

\begin{tabular}{|c|c|c|c|}
\hline Storey & $\begin{array}{c}\boldsymbol{F} \\
{[\mathbf{k N}]}\end{array}$ & $\begin{array}{c}\boldsymbol{Q} \\
{[\mathbf{k N}]}\end{array}$ & $\begin{array}{l}\boldsymbol{V}_{\text {link.Sd }} \\
{[\mathbf{k N}]}\end{array}$ \\
\hline \hline 1 & 18.9 & 680.4 & 340.2 \\
\hline 2 & 37.8 & 661.5 & 330.8 \\
\hline 3 & 56.7 & 623.7 & 311.9 \\
\hline 4 & 75.6 & 567.0 & 283.5 \\
\hline 5 & 94.5 & 491.4 & 245.7 \\
\hline 6 & 113.4 & 396.9 & 198.5 \\
\hline 7 & 132.3 & 283.5 & 141.8 \\
\hline 8 & 151.2 & 151.2 & 75.6 \\
\hline
\end{tabular}

The links are dimensioned by means of a simplified relationship which allows to determine the shear force acting on the link depending on the storey shear due to the design seismic horizontal forces [27]. In particular, the moment equilibrium equation around point A of (Fig. 4) can be applied at each storey. This equilibrium is based on the following assumptions: the member is subjected to a bi-triangular bending moment diagram with zero value at mid-span; the bending moment at the column bottom end is negligible. In these conditions, the following design formula is provided:

$$
\mathrm{V}_{\text {link.Sd }}=\frac{Q h}{L}
$$

where $Q$ is the storey seismic shear and $V_{\text {link.Sd }}$ is the shear internal action of the link. The quantity $V_{\text {link.Sd }}$ allows the dimensioning of the link section. In Table 1 the values corresponding to the 8 -storey EBFs are reported.



Fig. (4). Estimation of link design shear force.

In particular, in the case of short links, the cross section is chosen by imposing the following design condition:

$$
\mathrm{V}_{\text {link.Rd }} \geq \mathrm{V}_{\text {link.Sd }}
$$

being $V_{\text {link.Rd }}$ the design shear resistance. As underlined, EBFs have been designed both in the case of $e=70 \mathrm{~cm}$ and $\bar{e}=1.6$, using the same standard shapes distribution along 
the height of the structure. In the last case, the length of the link at each storey has been obtained by applying Eq. (6) for the current standard shape section.

In the case of long links, Eq. (8) is useful to determine the maximum bending action on the link, as provided by the following formula:

$$
\mathrm{M}_{\text {link.Sd }}=\frac{\mathrm{V}_{\text {link.Sd }} e}{2}
$$

which allows the dimensioning of the link section by means of the following design condition:

$$
\mathrm{M}_{\text {link.Rd }} \geq \mathrm{M}_{\text {link.Sd }}
$$

being $M_{\text {link.Rd }}$ the design resistance to bending moment. The length of the link at each storey has been obtained by applying Eq. (6) with $\bar{e}=3.0$. In particular, by expressing the design resistances by means of the ratio between the corresponding plastic values and the partial safety factor $\gamma_{M 0}$ (herein assumed equal to 1.1) [28]:

$$
\mathrm{V}_{\text {link.Rd }}=\frac{\mathrm{V}_{\mathrm{p}}}{\gamma_{M 0}} \mathbf{M}_{\text {link.Rd }}=\frac{\mathrm{M}_{\mathrm{p}}}{\gamma_{M 0}}
$$

it is easy to recognise that Eqs. (6), (10), (11) and (12) lead to the following design condition for long links:

$$
\mathrm{V}_{\text {link.Rd }} \geq \frac{\mathrm{V}_{\text {link.Sd }} \bar{e}}{2}
$$

which allows to dimension a long link directly by means of the maximum shear action and the selected value of the non-dimensional link length. Furthermore, in the case $\bar{e}=$ 3.0, Eq. (13) simplifies as the follows:

$$
\mathrm{V}_{\text {link.Rd }} \geq \frac{3}{2} \mathrm{~V}_{\text {link.Sd }}
$$

The comparison between Eq. (9) and Eq. (14) suggests that, independently of the length, the cross section required in case of long links is always greater than the case of a short link for a given storey shear action.

Finally, the design of intermediate links is based on a procedure proposed by the authors to account for momentshear interaction of the member both in plastic conditions and in ultimate conditions [20]. The procedure starts from the plastic interaction domain proposed by Neal [23], which is amplified by means of an homothetic expansion of $50 \%$ to account for strain-hardening effects to obtain the ultimate domain. It results that, for an assigned value $e$ of the intermediate link length, the plastic values of the bending moment and of the shear force are given by the following relationships [20]:

$$
\begin{aligned}
& M_{\text {intp }}=\frac{V_{p} e\left(M_{p}-M_{f p}\right) \sqrt{4 M_{p}\left(M_{p}-2 M_{f p}\right)+V_{p}^{2} e^{2}}-4 M_{f p}\left(M_{p}-M_{f p}\right)^{2}}{4\left(M_{p}-M_{f p}\right)^{2}+V_{p}^{2} e^{2}}+M_{f p} \\
& V_{\text {int.p }}=\frac{2 M_{\text {int.p }}}{e}
\end{aligned}
$$

being $M_{f p}$ the contribution of the flanges to the plastic moment of the section. If the plastic resistances expressed by Eqs. (15) and (16) are scaled to account for the partial safety factor $\gamma_{\mathrm{M} 0}$, they can be considered as design resistances ac- counting for moment-shear interaction occurring in intermediate links. In addition, the check of the member is satisfied provided that also all the code specifications are fulfilled, particularly those for $\mathrm{M}-\mathrm{V}$ interaction [28].

Therefore, starting from Eqs. (8) and (9), the intermediate link cross section can be selected by imposing the following design conditions:

$$
\begin{aligned}
& \frac{V_{\text {int.p }}}{\gamma_{M 0}} \geq V_{\text {link.Sd }} \\
& \frac{M_{\text {int.p }}}{\gamma_{M 0}} \geq M_{\text {link.Sd }}
\end{aligned}
$$

Bending and shear actions vary proportionally due to Eq. (10)); furthermore, the ultimate resistances in bending and shear do the same due to Eq. (16). Consequently, Eq. (17) and Eq. (18) are both satisfied provided that one of them is checked. Therefore, the design condition can be assumed as the following:

$$
M_{\text {links } S \mathrm{~s}} \leq\left[\frac{M_{p} \bar{e}\left(M_{p}-M_{f p}\right) \sqrt{4 M_{p}\left(M_{p}-2 M_{f p}\right)+M_{p}^{2} \bar{e}^{2}}-4 M_{f p}\left(M_{p}-M_{f p}\right)^{2}}{4\left(M_{p}-M_{f p}\right)^{2}+M_{p}^{2} \bar{e}^{2}}+M_{f p}\right] \frac{1}{\gamma_{M 0}}
$$

where $V_{p} e=M_{p} \bar{e}$ has been imposed due to Eq. (6). Eq. (19) is independent of the link length and, in the present work, has been applied with $\bar{e}=2.3$, as previously discussed. However, the choice of the cross section provided by Eq. (19) must be validated by checking also the respect of code specifications for $\mathrm{M}-\mathrm{V}$ interaction.

Finally, with reference to the local ductility supply of the link, an interpolation between the values \pm 0.09 rad and \pm 0.02 rad corresponding to short and long links, respectively, provides an ultimate rotation for intermediate links with $\bar{e}=$ 2.3 equal to $\pm 0.055 \mathrm{rad}[4,6-7]$.

As an example, in Table 2 the standard shape sections, made of S275 steel grade, and the corresponding link lengths are reported for the examined 8-storeys EBFs. In addition, the corresponding standard HEB sections of columns and diagonals resulting from the application of the Theory of Plastic Mechanism Control (TPMC) are reported in the same Table 2. The design conditions have been obtained by imposing that the mechanism equilibrium curve corresponding to the global mechanism has to be located below those corresponding to all the other undesired mechanisms, at least until the design displacement is reached.

The design displacement is defined as the value corresponding to a plastic rotation demand equal to the plastic rotation capacity under cyclic loading conditions. Starting from the following geometrical compatibility condition for split- $K$ EB-Frames:

$$
\theta L=\gamma e
$$

where $\theta$ is the plastic column rotation at the base of the structure and $\gamma$ is the plastic link rotation, the design displacement is computed as follows:

$$
\delta_{\mathrm{u}}=\theta_{p u} h_{n s}=\min \left\{\gamma_{u \cdot k} \frac{e_{k}}{L} h_{n s}\right\}_{k=1,2, \ldots, n_{s}}
$$

and it is governed by the shortest link, i.e. by the most involved dissipative zone. The design displacements used to 
Table 2. 8-Storeys EBFs: Designed Standard Sections

\begin{tabular}{|c|c|c|c|c|c|c|c|c|c|c|c|c|c|c|c|c|}
\hline \multirow{2}{*}{ Storey } & \multicolumn{4}{|c|}{$\begin{array}{l}\text { Short links } \\
(e=70 \mathrm{~cm})\end{array}$} & \multicolumn{4}{|c|}{$\begin{array}{l}\text { Short links } \\
(\bar{e}=1.6)\end{array}$} & \multicolumn{4}{|c|}{$\begin{array}{l}\text { Intermediate links } \\
\qquad(\bar{e}=2.3)\end{array}$} & \multicolumn{4}{|c|}{$\begin{array}{l}\text { Long links } \\
(\bar{e}=\mathbf{3 . 0})\end{array}$} \\
\hline & $\begin{array}{l}\text { Link } \\
\text { HEB }\end{array}$ & $\begin{array}{c}e \\
{[\mathbf{c m}]}\end{array}$ & $\begin{array}{l}\text { Diag. } \\
\text { HEB }\end{array}$ & $\begin{array}{l}\text { Col. } \\
\text { HEB }\end{array}$ & $\begin{array}{l}\text { Link } \\
\text { HEB }\end{array}$ & $\begin{array}{c}e \\
{[\mathrm{~cm}]}\end{array}$ & $\begin{array}{l}\text { Diag. } \\
\text { HEB }\end{array}$ & $\begin{array}{c}\text { Col. } \\
\text { HEB }\end{array}$ & $\begin{array}{l}\text { Link } \\
\text { HEB }\end{array}$ & $\begin{array}{c}e \\
{[\mathrm{~cm}]}\end{array}$ & $\begin{array}{l}\text { Diag. } \\
\text { HEB }\end{array}$ & $\begin{array}{c}\text { Col. } \\
\text { HEB }\end{array}$ & $\begin{array}{l}\text { Link } \\
\text { HEB }\end{array}$ & $\begin{array}{c}e \\
{[\mathrm{~cm}]}\end{array}$ & $\begin{array}{l}\text { Diag. } \\
\text { HEB }\end{array}$ & $\begin{array}{r}\text { Col. } \\
\text { HEB }\end{array}$ \\
\hline 1 & 260 & 70 & 240 & 360 & 260 & 146 & 260 & 360 & 320 & 249 & 300 & 400 & 340 & 328 & 320 & 320 \\
\hline 2 & 260 & 70 & 220 & 300 & 260 & 146 & 220 & 300 & 300 & 241 & 300 & 340 & 340 & 328 & 320 & 260 \\
\hline 4 & 240 & 70 & 220 & 240 & 240 & 130 & 220 & 240 & 280 & 222 & 260 & 240 & 320 & 325 & 300 & 200 \\
\hline 5 & 220 & 70 & 200 & 220 & 220 & 118 & 200 & 220 & 260 & 211 & 240 & 200 & 280 & 290 & 260 & 200 \\
\hline 6 & 180 & 70 & 200 & 200 & 180 & 94 & 200 & 200 & 220 & 170 & 200 & 160 & 260 & 276 & 240 & 140 \\
\hline
\end{tabular}

dimension the structures of Table $\mathbf{2}$ are listed in Table $\mathbf{3}$, where the ultimate plastic rotation $\gamma_{u}$ for each link typology is reported too. In particular, for the chosen short and intermediate links, the limits previously discussed for the ultimate cyclic rotation have been used (i.e. $\pm 0.09 \mathrm{rad}$ and $\pm 0.055 \mathrm{rad}$, respectively); conversely, in the case of long links, the selection of $\delta_{u}$ has been made on the basis of the theoretical plastic rotation capacity of the bent members [11]. Further details on this topic will be provided in next Section, with reference to long link modelling within nonlinear analyses.

Table 3. 8-Storeys EBFs: Design Displacements

\begin{tabular}{|c|c|c|c|}
\hline Typology & $\begin{array}{c}\boldsymbol{e}_{\min } \\
{[\mathbf{c m}]}\end{array}$ & $\begin{array}{c}\gamma_{u} \\
{[\mathbf{r a d}]}\end{array}$ & $\begin{array}{c}\boldsymbol{\delta}_{u} \\
{[\mathbf{c m}]}\end{array}$ \\
\hline \hline short links $(e=70 \mathrm{~cm})$ & 70 & 0.09 & 25.2 \\
\hline short links $(\overline{\boldsymbol{e}}=1.6)$ & 75 & 0.09 & 27.0 \\
\hline intermediate links $(\overline{\boldsymbol{e}}=2.3)$ & 93 & 0.055 & 20.46 \\
\hline long links $(\overline{\boldsymbol{e}}=3.0)$ & 143 & 0.101 & 57.83 \\
\hline
\end{tabular}

\section{PUSH-OVER ANALYSES}

In order to evaluate the seismic behaviour of the designed structures, push-over analyses have been preliminarily carried out for the designed EBFs. In particular, such analyses have the primary aim to predict the pattern of yielding to be directly compared with the global failure mode representing the main goal of the design methodology.

Push-over analyses have been carried out by means of SAP 2000 program [26]. They have been led under displacement control, taking into account both geometrical and mechanical non-linearities. In addition, out-of-plane stability checks of all members have been performed by postprocessing the analysis results.

The most important issue in the modelling of EB-Frames is the link modelling, because of the paramount role of mo- ment-shear interaction. This topic has been investigated by many researchers [20, 22, 29-35] providing different modelling techniques, depending also on the type of analyses, either elastic-plastic or rigid-plastic, to be performed.

In this work, all the members have been modelled by means of beam-column elements, whose non-linearities have been concentrated in plastic hinges at their ends. In particular, plastic hinges accounting for the interaction between axial force and bending moment have been defined for columns, diagonals and beam parts outside of the link. With reference to the link modelling, according to the overstrength effect previously discussed, member behaviour has been described by means of a bi-linear curve accounting for strain-hardening, both in the case of shear and flexural hinges (i.e. with reference to each kind of link ultimate behaviour). Furthermore, the hardening ratio of the above mentioned bi-linear curve has been modelled on the basis of the experimental monotonic behaviour. To this scope, the monotonic value is chosen for the ultimate deformation $\gamma_{u}$. Therefore, for short links the value $\gamma_{u}=0.20 \mathrm{rad}$ [7] has been adopted, while for long links the theoretical rotation capacity of bent members has been considered. In particular, long links (which are approximately subjected to a bi-triangular diagram of bending moment with zero value at mid-span) constitute an assembly of two cantilever beams, whose rotation capacity can be compared with that provided by a centrally loaded beam, usually adopted as test specimen [11, 36]. Following this approach, if a proportional relationship between the slope of the long link moment-rotation curve and the slope of the $\sigma-\varepsilon$ constitutive law of the material is assumed, a strain-hardening corresponding at approximately $2 \div 3 \%$ is obtained. Finally, for intermediate links, since experimental monotonic tests are not available, a linear interpolation between short and long link values has been adopted [7].

In particular, short links have been modelled by means of beam-column elements with plastic hinges at their ends whose properties have been defined by means of the equivalent plastic moment concept [20]. In particular, a rigid-strainhardening bi-linear curve has been assigned to the plastic 
hinges and an ultimate deformation equal to $\gamma_{u}$ has been assumed. In fact, the elastic phase of link behaviour is directly taken into account by means of the beam-column element representing the link.

Furthermore, also with reference to intermediate and long links, plastic hinges in simple bending, with rigid-hardening response, have been adopted to model the plastic behaviour of the member ends. The equivalent plastic moment previously briefly discussed (see Eqs. (1) $\div(3)$ ) has been adopted for intermediate links. This tool allows to deal with intermediate links like with members collapsing in pure bending, provided that an equivalent ultimate moment accounting for moment-shear interaction is properly defined.

Aiming to compare the results provided by the analysed EBF schemes, the patterns of yielding and the $\alpha-\delta$ curves resulting from push-over analyses have been preliminarily compared. In particular, the results concerning the 8-storeys EBFs, whose properties are summarised in Table 2, are discussed in this paper; similar results have been obtained for all the other analysed schemes [10]. In Fig. (5) the patterns of yielding are shown for each link typology; in particular, for sake of simplicity, only the EB-Frames are depicted, while the pinned parts (i.e. gravity columns) of the structures outside of the brace are not reported, being ineffective in terms of plastic hinges distribution, even if they have been considered in the analyses in order to properly account for second order effects coming from the total vertical loads. Patterns of yielding are depicted with reference to the displacement level $\delta_{c}$ corresponding to the attainment of the ultimate deformation in one of the plastic hinges. Plastic hinge distribution is in perfect agreement with the design goal, i.e. the development of a collapse mechanism of global type. In addition, in (Fig. 6) the $\alpha-\delta$ curves (multiplier of design seismic horizontal forces versus top sway displace- ment) obtained by means of push-over analyses are reported.

The accuracy of the proposed design methodology, already assessed and underlined in $[8,10]$, has been confirmed also in the case of a variable distribution of the link lengths along the building height. In fact, Fig. (5) points out that all the dissipative zones, i.e. all the links, are involved in the pattern of yielding, while non-dissipative zones, i.e. columns, braces and beam parts outside of links, are not involved with the only exception of base sections of first order columns and diagonals. Only in the case of long links an undesired hinge developed at the beam-to-link connection of $7^{\text {th }}$ storey, but this does not affect the accuracy of the obtained result, because such hinge does not rotate being a "spurious" hinge not participating to the kinematics of the collapse mechanism. Therefore, the patterns of yielding are in perfect agreement with the design goal, i.e. the global mechanism. In addition, it can be observed that in the cases of short links with $\bar{e}=1.6$ and long links, when the ultimate displacement is attained due to local ductility limitations, the kinematic plastic mechanism is completely developed.

Moreover, the $\alpha-\delta$ curves show high energy dissipation capacity and satisfactory global ductility for all the structures. In addition, it is useful to point out that the available global ductility of EBFs characterised by links having different length along the building height is greater than that of the EBF with short links having all the same length. This result seems to suggest the convenience of the adopted link length selection criterion $(\bar{e}=1.6)$, which is aimed at the limitation of the link plastic rotation demands. However, this conclusion must be properly verified by means of dynamic nonlinear analyses to account also for the influence of the period of vibration, because of the different lateral stiffness provided by the different structural solutions, and higher modes effects.
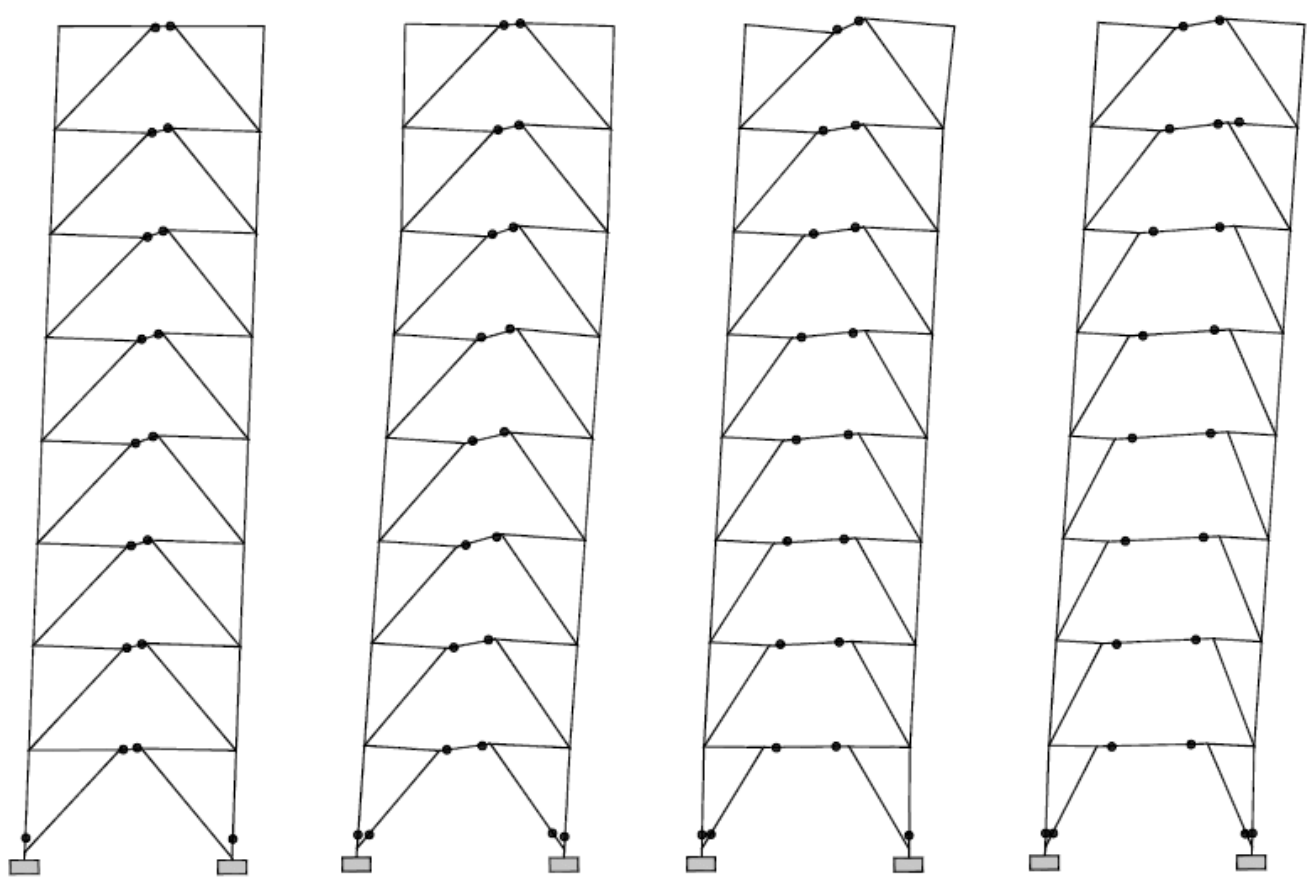

Fig. (5). 8-storeys EBFs: patterns of yielding under push-over analyses. 


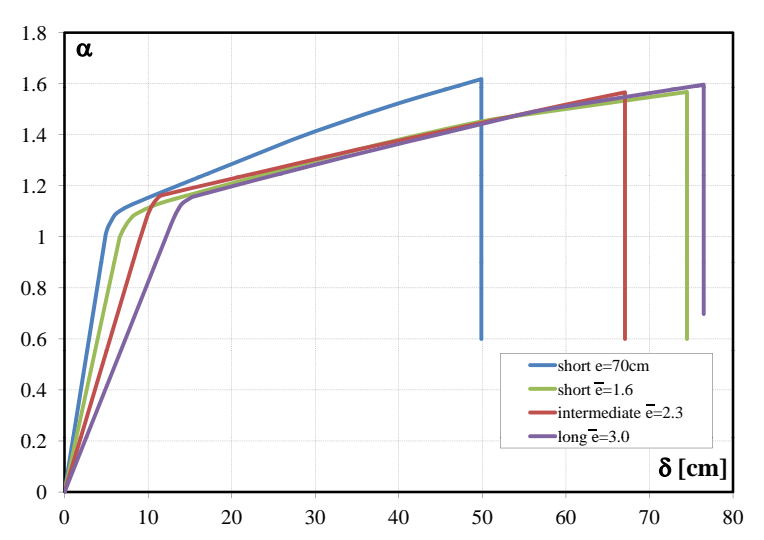

Fig. (6). 8-storeys EBFs: push-over curves.

\section{INCREMENTAL DYNAMIC ANALYSES}

As it is well known, push-over analyses have the primary limit to neglect the influence of higher modes of vibration. This circumstance could be particularly significant for braced frames whose adoption becomes more and more convenient with respect to MR-Frames as far as the number of storeys increases.

Therefore, the actual performance of the designed EBFs can be better assessed by means of dynamic non-linear analyses carried out for increasing values of a ground motion intensity measure (namely incremental dynamic analyses or IDA). In fact, this kind of analysis, taking into account also higher order vibration modes and their influence on the pattern of yielding, provides the best prediction of the seismic response of structures, pointing out the actual local and global ductility demands.

These analyses have been carried out by means of SAP 2000 computer program [26]. A preliminary analysis has been carried out considering an artificial record to simulate a ground motion matching Eurocode 8 design spectrum for $\mathrm{C}$ type soil. Successively, a more wide analysis has been carried out with reference to historical records. To this scope, seven earthquake records selected from the PEER database [37] have been considered. The details of the selected records are given in Table 4.
The structures have been modelled as an assembly of beam-column elements with plastic hinges at their ends. In particular, columns, braces and beams outside of the links have been modelled by means of beam-column elements whose plastic hinges, located at their ends, are characterised by a rigid-perfectly plastic behaviour based on an axial force-bending moment interaction domain defined according to the plastic domain provided by Eurocode 3 [28].

Moreover, particular care has been taken in modelling the link element. Similarly to the case of push-over analyses, the concept of equivalent plastic moment has been adopted in plastic hinge definition assuming, for short links, an ultimate plastic rotation equal to $\pm 0.09 \mathrm{rad}$ [4,6-7]. Elastic shear and flexural deformations are already included due to the beamcolumn element representing the actual link member, so that the adoption of a rigid-hardening behaviour for the plastic hinge is fully justified. Also, intermediate and long links have been treated according to the same models, but assuming an ultimate plastic rotation equal to $\pm 0.055 \mathrm{rad}$ and \pm 0.02 rad [7] for intermediate and long links, respectively.

Viscous damping has been assumed equal to $5 \%$ adopting proportional damping according to the Rayleigh modelling.

The attention has also been paid to the possibility of occurrence of out-of-plane buckling of columns; therefore all the members have been also checked against buckling by properly post-processing IDA results in terms of internal actions at each time step and for each ground motion intensity measure.

The dynamic response of the designed structures has been evaluated by investigating the pattern of yielding, the maximum plastic deformation demands and the maximum absolute and relative displacements corresponding to each ground motion. In particular, in order to compare these results with the ones provided by push-over analyses, the 8storeys EBFs are herein examined in detail.

As already stated, a preliminary analysis has been carried out with reference to an artificial record matching Eurocode 8 spectrum for subsoil class C (EC8-C). In Fig. (7) the maximum required plastic deformations of links are reported for increasing values of the peak ground acceleration $(P G A)$. Moreover, (Fig. 8) provides for each structure the plastic hinges envelopes and the corresponding maximum plastic

Table 4. Details of Ground Motion Records Selected for IDA Analyses

\begin{tabular}{|c|c|c|c|c|c|}
\hline Earhquake (record) & Component & Date & PGA/g & Length (s) & Step recording (s) \\
\hline Victoria, Mexico (Chihuahua) & CHI102 & 1980/06/09 & 0.150 & 26.91 & 0.01 \\
\hline Coalinga (Slack Canion) & $\mathrm{H}-\mathrm{SCN} 045$ & $1985 / 05 / 02$ & 0.166 & 29.99 & 0.01 \\
\hline Kobe (Kakogawa) & KAK000 & $1995 / 01 / 16$ & 0.251 & 40.95 & 0.01 \\
\hline Northridge (Stone Canyon) & SCR000 & $1994 / 01 / 17$ & 0.252 & 39.99 & 0.01 \\
\hline Imperial Valley (Agrarias) & H-AGR003 & $1979 / 10 / 15$ & 0.370 & 28.35 & 0.01 \\
\hline Santa Barbara (Courthouse) & SBA132 & $1978 / 08 / 13$ & 0.102 & 12.57 & 0.01 \\
\hline Friuli, Italy (Tolmezzo) & TMZ000 & $1976 / 05 / 06$ & 0.351 & 36.35 & 0.005 \\
\hline
\end{tabular}




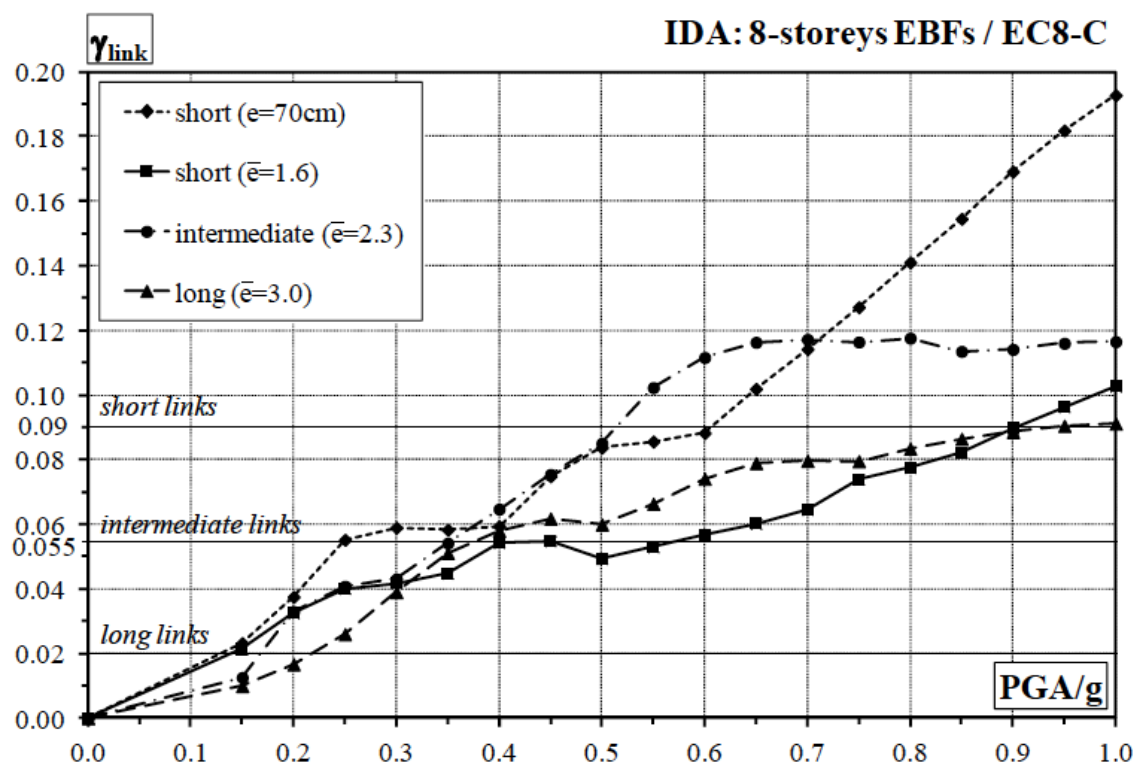

Fig. (7). 8-storeys EBFs: IDA maximum plastic link deformations (EC8-C).
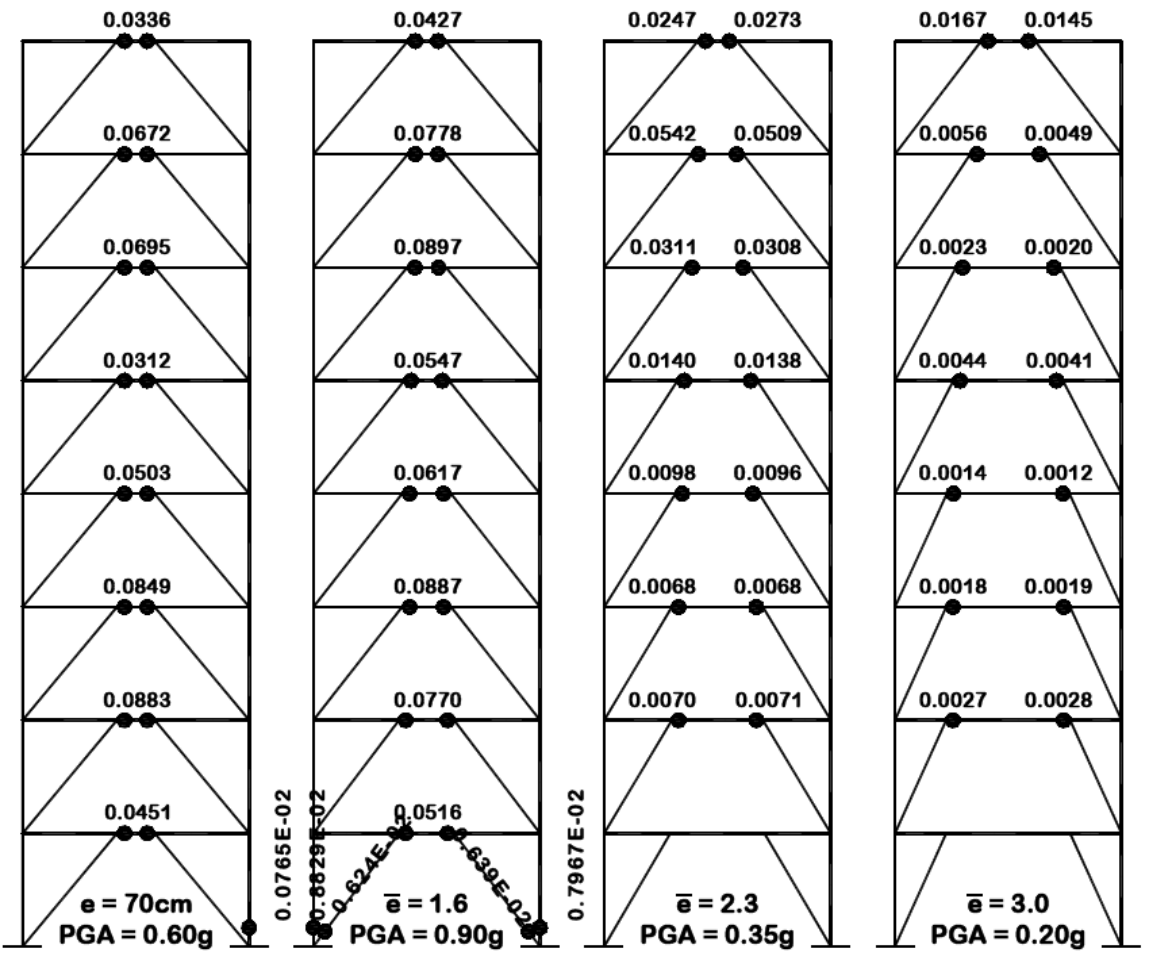

Fig. (8). 8-storeys EBFs: IDA plastic hinges envelopes (EC8-C).

rotation values for the $P G A$ value corresponding to the achievement of a maximum local ductility demand practically equal to the link reserves under cyclic loading (i.e. $\approx$ \pm 0.09 rad for short links, $\approx \pm 0.02$ rad for long links, $\approx \pm 0.055$ rad for intermediate links, as previously discussed). Therefore, each plastic hinge envelope of (Fig. 8) represents the pattern of yielding in the collapse prevention limit state.

Finally, in Fig. (9 and Fig. 10) the roof displacement angles $(R D A=\Delta / H$, the ratio between the maximum absolute top sway displacement and the building height) and the maximum interstorey drift ratios $\left(M I D R=\delta_{\max } / h\right.$, being $\delta_{\max }$ the maximum storey relative displacements and $h$ the interstorey height) are shown, respectively. It is useful to point out that similar results have been obtained for all the analysed structures, so that the observations coming out in the following can be generalised independently of the number of storeys.

All the analysed structures are characterised by an excellent pattern of yielding. In fact, for increasing values of $P G A$, yielding occurs in all the links, or almost (Fig. 8), so that high dissipation capacity and adequate inelastic performances are achieved. This result confirms the fulfilment 


\section{RDA= $\mathbf{A} \mathbf{H}$}

\section{IDA: 8-storeys EBFs / EC8-C}

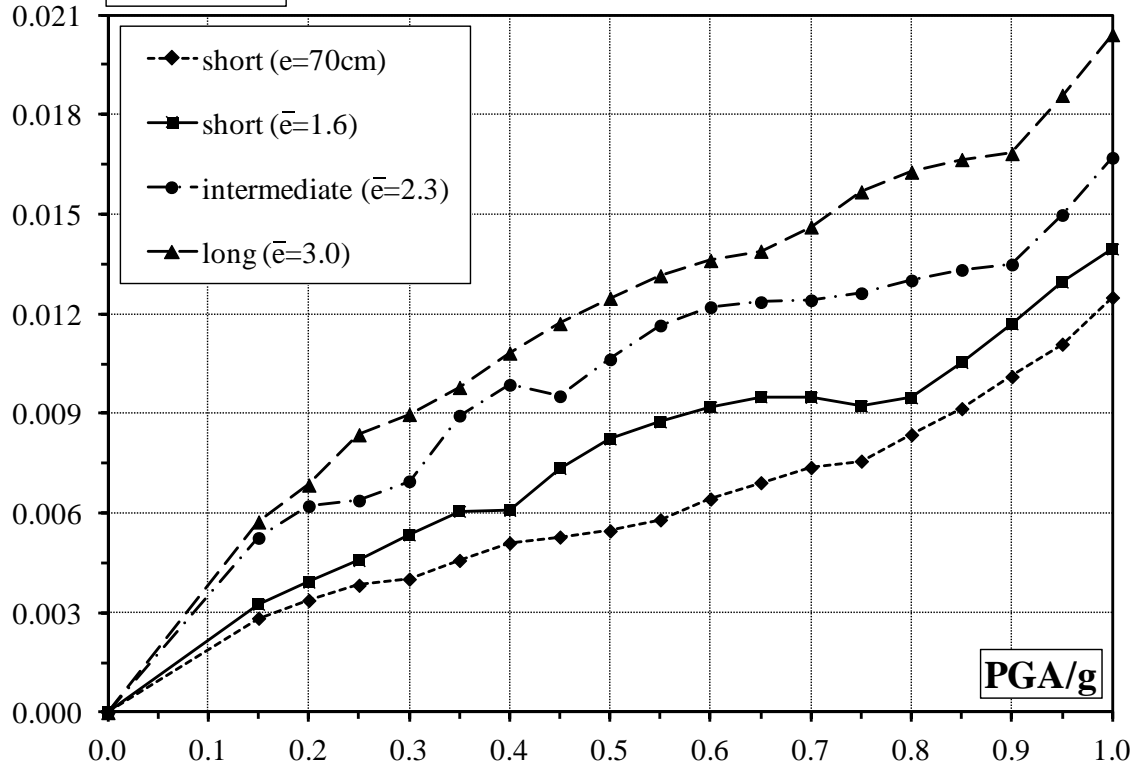

Fig. (9). 8-storeys EBFs: IDA maximum absolute. non-dimensional displacements (EC8-C).

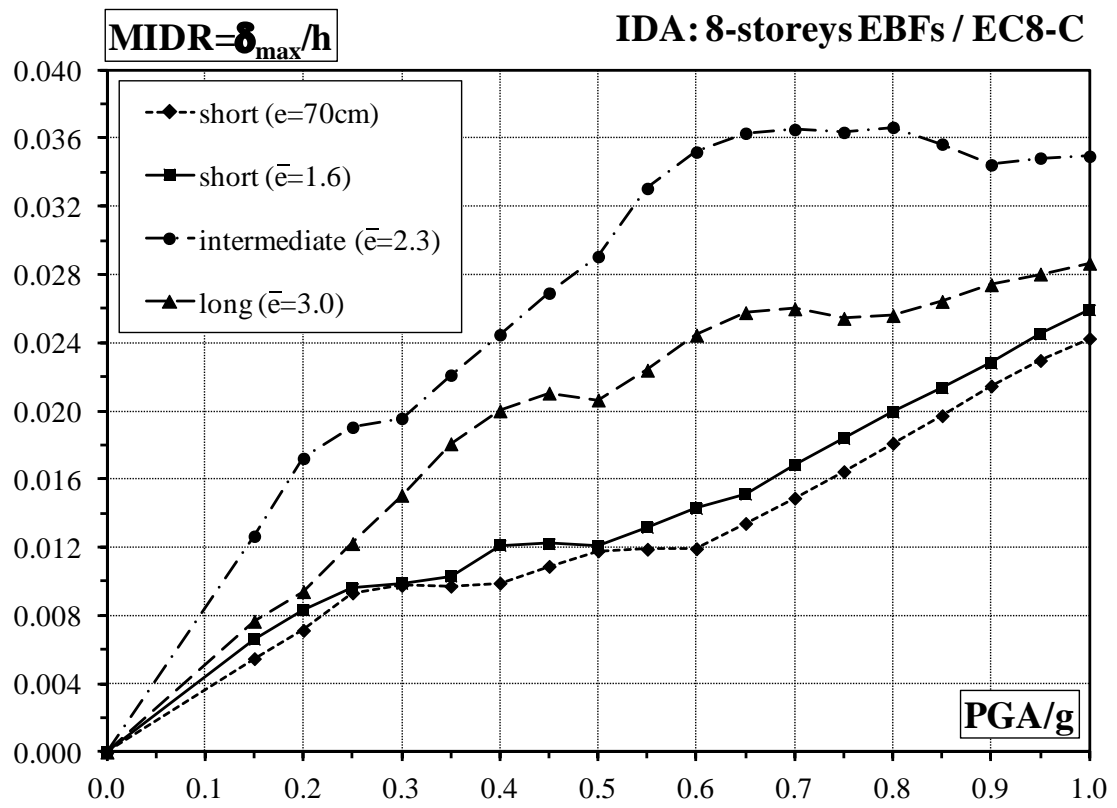

Fig. (10). 8-storeys EBFs: IDA maximum relative. non-dimensional displacements (EC8-C).

of the design goal (i.e. the development of a collapse mechanism of global type) in agreement with the results of pushover analyses. In fact, even if not all the plastic hinges in the envelopes are sufficient to activate a kinematic mechanism, the pattern of yielding evidently tends to the global mechanism since no plastic hinges develop in non-dissipative zones. In particular, in the case of short links with $\bar{e}=1.6$ the plastic hinge distribution fully corresponds to the global mechanism with the plasticity involving all the links and only the base sections of columns and diagonals.

Regarding the link plastic deformations, despite of the drawback coming from the geometrical configuration $(\gamma=\theta$ $L / e$ ), short links with $\bar{e}=1.6$ are usually subjected to the lowest values of the plastic rotation demands (Fig. 7). This result can be justified by means of several considerations. The first one is that the lateral stiffness of EB-frames with intermediate and long links is lower than the case of short links (see the elastic branches in Fig. 6), so that the interstorey drifts increase (Fig. 10). Furthermore, dynamic analyses show that the maximum values of the link plastic deformation occur, in the case of intermediate and long links, at the top storeys (Fig. 8), where link lengths are quite small when compared with those at bottom storeys. Therefore, in this case the geometrical configuration is responsible of high plastic rotation demands for the top storeys links. In addition, as far as the number of storeys increases, the effects of high order vibration modes become more and more signifi- 
cant, so that second and third vibration modes give rise to a further concentration of plastic deformations in top storeys links [10].

Moreover, as previously underlined, the maximum values of plastic rotations have to be compared with the cyclic local ductility supply provided by each link typology. With reference to (Fig. 7), short links reach $0.09 \mathrm{rad}$ for a $P G A$ value equal to $0.60 \mathrm{~g}$ and $0.90 \mathrm{~g}$, in the cases of $\mathrm{e}=70 \mathrm{~cm}$ and $\bar{e}=$ 1.6, respectively. Furthermore, the ultimate link rotations are reached at $0.35 \mathrm{~g}$ and $0.20 \mathrm{~g}$ for intermediate and long links, respectively. Therefore, short links with $\bar{e}=1.6$ allows to withstand ground motions with high $P G A$ before fracture of links occurs, while the complete exploitation of the local ductility supply is prematurely reached in case of intermediate and long links. In particular, in the case of long links, the quite small local ductility supply, at least with reference to the experimental tests reported in [7], is responsible of the premature link collapse for low $P G A$ values.

Some useful considerations must be also pointed out on the irregular behaviour of the curves depicted in (Fig. 7, Fig. 9 and Fig. 10). In fact, significant variations of the curve slopes can be recognised at different $P G A$ ranges, showing counter-intuitive reductions of the depicted quantities even if the intensity of the earthquake increases. Indeed, not all the analysed structures show the same kind of response, even if several of them are characterised by such non-monotonic behaviours.

It is well known that IDA curves often provide this kind of results, as thoroughly discussed by Vamvatsikos and Cornell [38]. In fact, segments of softening or hardening can be provided after the initial stiffness of the structure, i.e. regions where the slope of the curve decreases with higher intensity measures or other regions where such slope increases. This means that the structure can experience an acceleration responsible of damage accumulation, but at the following time it is subjected to a deceleration that can be powerful enough to momentarily stop the damage accumulation or even reverse it. So the IDA curve is characterised by lower damage measures and it becomes a non-monotonic function of the seismic intensity measure. In particular, the examined case is analogous to the case of severe hardening [38]. In fact, the system shows an high response for a given intensity level, but exhibits the same or lower response for higher seismic intensities due to excessive hardening. Within this issue, it is the pattern and timing of the accelerogram rather than just the intensity that govern the response. As the earthquake is scaled up, weak response cycles in the early part of the response time-history become amplified enough to generate yielding, so that the structural properties result modified when the stronger cycles are reached. The extreme case of hardening leads to the case in which a structure reaches the global collapse for an intensity measure but not for an higher one, reappearing with high response but still in an equilibrium state. This issue is known as structural resurrection [38].

The investigation of the seismic response of the designed EB-Frames has been widened considering the influence of record-to-record variability. To this scope, the seven historical records described in Table 4 have been considered to perform additional IDA analyses where the spectral accelera- tion corresponding to the fundamental period of vibration of the structure has been adopted as seismic Intensity Measure (IM). In fact, it is well known that the use of such IM is more efficient, compared to the PGA, reducing the scatters in seismic response due to record-to-record variability [39-46].

Therefore, IDA analyses have been carried out for increasing values of the spectral acceleration corresponding to the fundamental period of vibration of the structure $\left(\mathrm{T}_{1}=0.864 \mathrm{~s}\right.$ for the EB-Frame with short links having constant length $\mathrm{e}=70 \mathrm{~cm} ; \mathrm{T}_{1}=1.027 \mathrm{~s}$ for the EB-Frame with short links having constant non-dimensional length $\overline{\mathrm{e}}=1.6$; $\mathrm{T}_{1}=1.175 \mathrm{~s}$ for the EB-Frame with intermediate links having $\overline{\mathrm{e}}=2.3 ; \mathrm{T}_{1}=1.345 \mathrm{~s}$ for the EB-Frame with long links having $\overline{\mathrm{e}}=3.0$ ).

In Fig. (11), with reference to the four examined EBFrames, the maximum plastic rotation demand of links is provided for increasing values of the spectral acceleration corresponding to the period of vibration of the relevant structural scheme. The obtained IDA curves are quite irregular as already discussed with reference to the seismic response under the simulated accelerogram (EC8-C). The influence of record-to-record variability is evident. Therefore, reference will be made to the average IDA curve. In particular, it can be observed that the ultimate plastic rotation capacity of links is attained, on average, for $S_{a}\left(T_{1}\right) \cong 1.18 \mathrm{~g}$ for the EBFrame with short links having constant length $\mathrm{e}=70 \mathrm{~cm}$, for $\mathrm{S}_{\mathrm{a}}\left(\mathrm{T}_{1}\right) \cong 1.05 \mathrm{~g}$ for the EB-Frame with short links having constant non-dimensional length $\overline{\mathrm{e}}=1.6$; for $\mathrm{S}_{\mathrm{a}}\left(\mathrm{T}_{1}\right) \cong 0.31 \mathrm{~g}$ for the EB-Frame with intermediate links having $\overline{\mathrm{e}}=2.3$ and for $\mathrm{S}_{\mathrm{a}}\left(\mathrm{T}_{1}\right) \cong 0.16 \mathrm{~g}$ for the EB-Frame with long links having $\overline{\mathrm{e}}=3.0$. Therefore, even in the case of historical records and also considering the influence of record-to-record variability, it can be concluded that the seismic performance of EBFrames is mainly governed by the plastic rotation capacity of links, so that EB-Frames with short links lead to ultimate values of the spectral acceleration significantly increased when compared with those occurring in case of both intermediate and long links. In the examined cases, the use of short links provide similar performances both in case of constant link length and in case of constant non-dimensional link length.

In Fig. (12), IDA curves are also provided for the maximum interstorey drift ratio versus spectral acceleration. The beneficial effects of bracings are obviously related to the link length, because, as it is well known, the lateral stiffness of the structure increases as far as the link length decreases. As a consequence, an increase of the spectral acceleration corresponding to the attainment of a given limit value of the maximum interstorey drift ratio is expected examining EBFrames with reducing link length, i.e. passing from long links to short links. As an example, if reference is made to a limit value of MIDR equal to $0.02 \mathrm{rad}$, the corresponding limit value of the spectral acceleration is, on average, equal to $\mathrm{S}_{\mathrm{a}}\left(\mathrm{T}_{1}\right) \cong 0.40 \mathrm{~g}$ in case of long links $(\overline{\mathrm{e}}=3.0), \mathrm{S}_{\mathrm{a}}\left(\mathrm{T}_{1}\right) \cong 0.54 \mathrm{~g}$ in case of intermediate links $(\overline{\mathrm{e}}=2.3), \mathrm{S}_{\mathrm{a}}\left(\mathrm{T}_{1}\right) \cong 0.90 \mathrm{~g}$ in case of short links with constant non-dimensional link length $(\overline{\mathrm{e}}=1.6)$ and $\mathrm{S}_{\mathrm{a}}\left(\mathrm{T}_{1}\right) \cong 1.35 \mathrm{~g}$ in case of short links with constant length $(\mathrm{e}=70 \mathrm{~cm})$. This last solution, therefore, seems to provide the best behaviour considering that the reduction of lateral displacements provides also a significant reduction of nonstructural damage. 

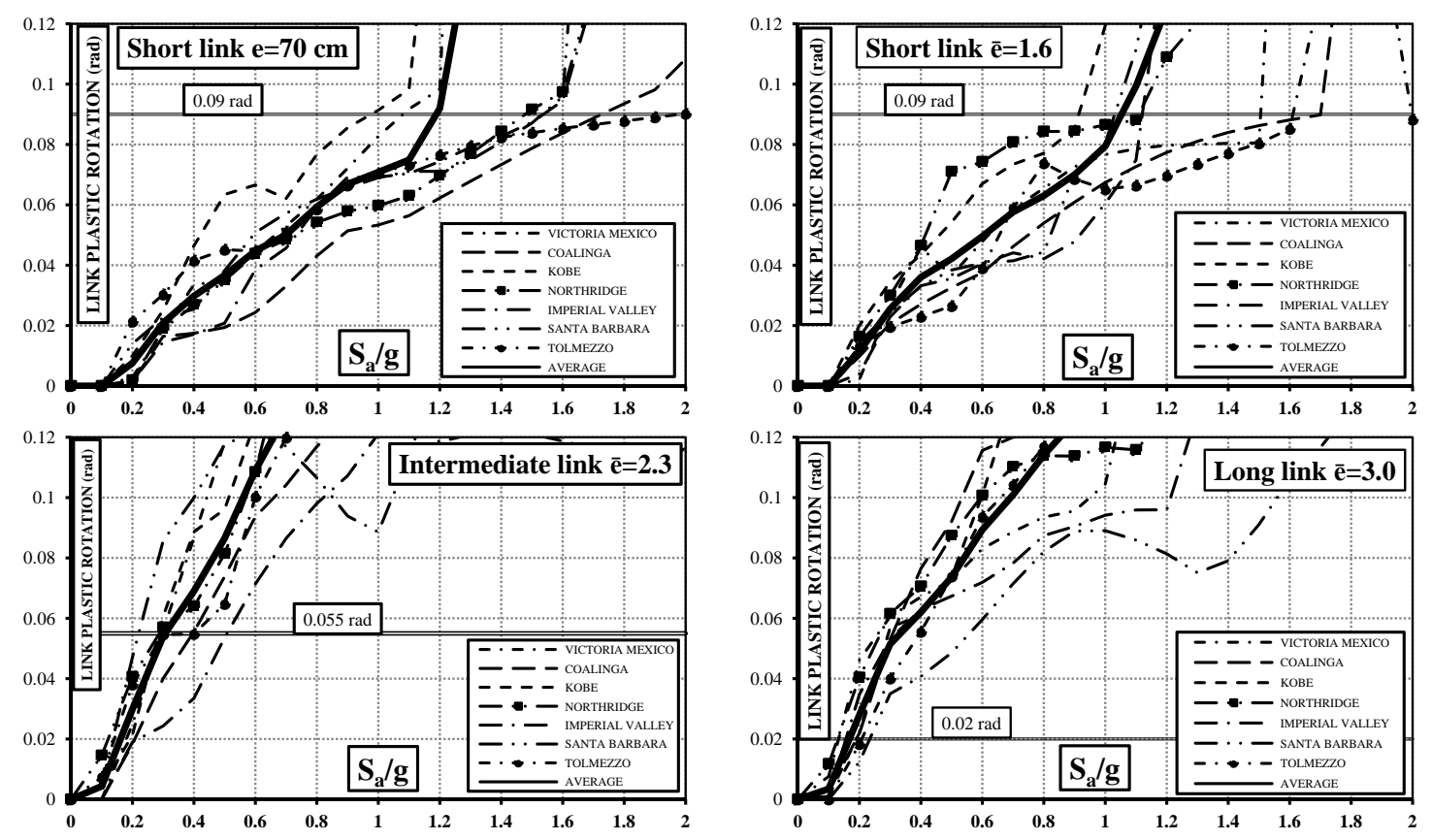

Fig. (11). IDA curves relating the maximum link plastic rotation to the spectral acceleration.
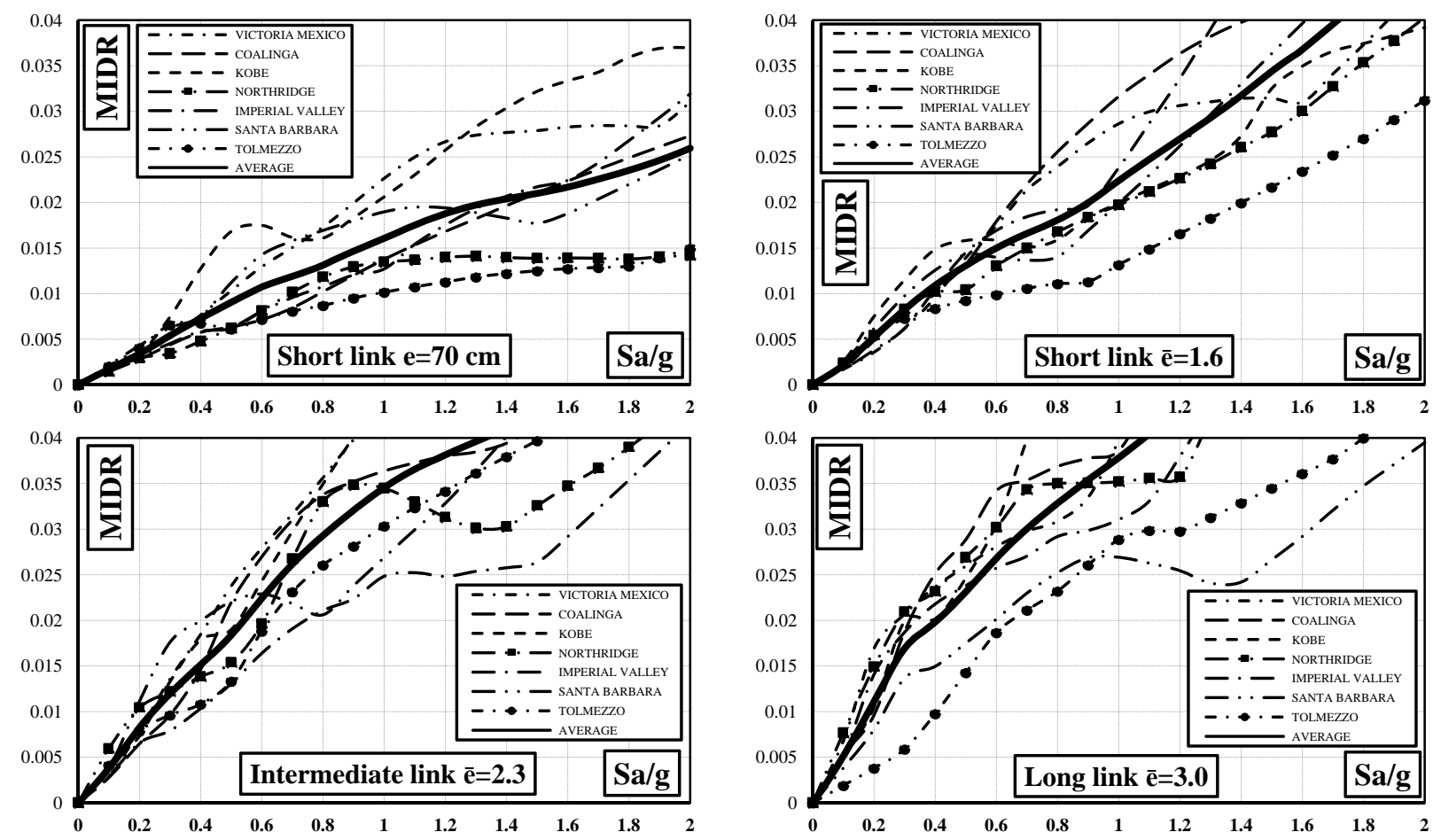

Fig. (12). IDA curves for MIDR versus spectral acceleration.

It is also important to underline that all the IDA analyses herein carried out have always pointed out the development of a pattern of yielding in perfect agreement with a collapse mechanism of global type, as already depicted in (Fig. 8) with reference to EC8-C record.

Finally, the comparison between the analysed structural schemes can be performed in terms of structural weight.

With reference to the 8-storeys EBFs, the following weights are obtained: $116 \mathrm{kN}$ for $\mathrm{e}=70 \mathrm{~cm}, 116 \mathrm{kN}$ for $\bar{e}=1.6,126$ $\mathrm{kN}$ for $\bar{e}=2.3$ and $131 \mathrm{kN}$ for $\bar{e}=3.0$. The results for different number of storeys are similar, being EBFs with intermediate and long links usually characterised by the highest values of the structural weight. 


\section{CONCLUSIONS}

All the EBFs herein examined have been designed by means of a design procedure able to guarantee a collapse mechanism of global type. The validation of the proposed design procedure has been carried out both by push-over and IDA analyses confirming its accuracy.

The seismic response of eccentrically braced frames with different link lengths has been studied with reference to the same design approach, i.e. the assurance of a global mechanism, so that the link length influence has been investigated among structures characterised by the same failure mode.

The selection of the link length has been led according to a new criterion which is based on the definition of the link non-dimensional length. This criterion is aimed at calibrating the same ultimate behaviour for all the links along the structure height, and it allows to control some main design parameters such as the local ductility demands and the lateral stiffness of the structure.

Both push-over analyses and dynamic non-linear analyses have been carried out for EBFs with short, intermediate and long links selected by means of the above mentioned criterion. The results show that the choice of short links provides the best results. In fact, such structures are characterised by high global ductility, high energy dissipation capacity and local ductility demands compatible with the corresponding supply for high values of the spectral acceleration. In addition, they exhibit adequate lateral stiffness when compared with EBFs having intermediate and long links thus reducing the maximum interstorey drift ratio and, as a consequence, damage to non-structural components.

Conversely, EBFs with long links are affected by the achievement of the maximum available local ductility for low values of $S_{a}$, leading to the premature collapse of the structure without the complete exploitation of the plastic reserves.

\section{CONFLICT OF INTEREST}

The author(s) confirm that this article content has no conflicts of interest.

\section{ACKNOWLEDGEMENT}

Declared none.

\section{REFERENCES}

[1] K.D. Hjelmstad, and E.P. Popov, "Characteristics of eccentrically braced frames", Journal of Structural Engineering, ASCE, vol. 110, no. 2, pp. 340-353, 1984.

[2] P.W. Richards, "Estimating the stiffness of eccentrically braced frames", Practice Periodical on Structural Design and Construction, ASCE, vol. 15, no. 1, pp. 91-95, 2010.

[3] K. Kasai, and E.P. Popov, "General behaviour of WF steel shear link beams", Journal of Structural Engineering, ASCE, vol. 112, no. 2, pp. 362-382, 1986.

[4] T. Okazaki, G. Arce, H.C. Ryu, and M.D. Engelhardt, "Resent Research on Link Performance in Steel Eccentrically Braced Frames", 13th World Conference on Earthquake Engineering, 13th WCEE, Vancouver, Canada, August 1-6, 2004, Paper no. 302, 2004.

[5] M. Ohsaki, and T. Nakajima, "Optimization of link member of eccentrically braced frames for maximum energy dissipation", Journal of Constructional Steel Research, vol. 75, pp. 38-44, 2012.
[11] F.M. Mazzolani, and V. Piluso, "Theory and Design of Seismic Resistant Steel Frames", E \& FN Spon, an Imprint of Chapman \& Hall, London, 1996.

[12] F.M. Mazzolani, and V. Piluso, "Plastic design of seismic resistant steel frames", Earthquake Engineering and Structural Dynamics, vol. 26, no. 2, pp. 167-191, 1997.

[13] L. Mastrandrea, and V. Piluso, "Seismic Design of MRF-EBF Dual Systems: Design Procedure for Failure Mode Control", Proceedings of Eurosteel 2011, 6th European Conference on Steel and Composite Structures, Budapest, Hungary, August 31-September 2, 2011.

[14] M.A. Conti, L. Mastrandrea and V. Piluso, "Plastic Design and Seismic Response of Knee Braced Frames", Advanced Steel Construction, September 2009, Vol. 5, No. 3, pp. 343-366, 2009.

[15] M.A. Conti, L. Mastrandrea, and V. Piluso, "Plastic Design of Seismic Resistant Knee Braced Frames", Proceedings of STESSA 2006, 5th International Conference on Behaviour of Steel Structures in Seismic Areas, Yokohama, Japan, August 14-17 2006.

[16] M.A. Conti, L. Mastrandrea, and V. Piluso, "Dynamic Response of Knee Braced Frames Designed for Failure Mode Control", Proceedings of ICSAS Conference 2007, 6th International Conference on Steel and Aluminium Structures, Oxford, England, July 24-27, 2007.

[17] A. Longo, R. Montuori, and V. Piluso, "Theory of plastic mechanism control of dissipative truss moment frames", Engineering Structures, vol. 37, pp. 63-75, 2012.

[18] A. Longo, R. Montuori, and V. Piluso, "Failure mode control of Xbraced frames under seismic actions", Journal of Earthquake Engineering, vol. 12, no. 5, pp. 728-759, 2008.

[19] A. Longo, R. Montuori, and V. Piluso, "Plastic design of Seismic resistant V-braced frames", Journal of Earthquake Engineering, vol. 12, no. 8, pp. 1246-1266, 2008.

[20] L. Mastrandrea, and V. Piluso, "Plastic design of eccentrically braced frames: I: Moment-shear interaction", Journal of Constructional Steel Research, vol. 65, no. 5, pp. 1007-1014, 2009.

[21] M.A. Conti, L. Mastrandrea, and V. Piluso, "Theoretical analysis of moment-shear interaction in knee braced frames", Proceedings of STESSA 2006,5 th International Conference on Behaviour of Steel Structures in Seismic Areas, Yokohama, Japan, August 14-17, 2006.

[22] R. Montuori, E. Nastri, and V. Piluso, "Rigid-plastic analysis and moment-shear interaction for hierarchy criteria of inverted Y EBframes" (Accepted) Journal of Constructional Steel Research, 2014

[23] B.G. Neal, "Effect of shear force on the fully plastic moment of an I-beam", Journal of Mechanics and Engineering Science, vol. 3, no. 3, pp. 258-267, 1961.

[24] E.P. Popov, and M.D. Engelhardt, "Seismic eccentrically braced frames", Journal of Constructional Steel Research, vol. 10, pp. 321-354, 1988.

[25] EN 1998-1-1, "Eurocode 8: Design of Structures for Earthquake Resistance. Part 1: General Rules, Seismic Actions and Rules for Buildings", Comité Europeén de Normalisation, CEN/TC 250, Bruxelles, 2004.

[26] CSI, "SAP 2000: Integrated Finite Element Analysis and Design of Structures. Analysis Reference.", Computers and Structures Inc., University of California, Berkeley, 2007.

[27] K. Kasai, and X. Han, "New EBF Design Method and Applications: Redesign and Analysis of U.S.-Japan EBF", Proceedings of 
STESSA 97, 2nd International Conference on Behaviour of Steel Structures in Seismic Areas, Kyoto, Japan, August 3-8, 1997.

[28] EN 1993-1-1, "Eurocode 3: Design of Steel Structures. Part 1: General Rules and Rules for Buildings", Comité Europeén de Normalisation, CEN/TC 250, Bruxelles.

[29] M.F. Giberson, "The response of non-linear multi-story structures subjected to earthquake excitation", Ph.D. Dissertation, Pasadena, California Institute of Technology, 1967.

[30] F.L. Porter, and G.H. Powell, "Static and dynamic analysis of inelastic frame structures", EERC Report No. 71-3, Berkeley: Earthquake Engineering Research Center, University of California, 1971.

[31] P.F. Chen, and G.H. Powell, "Generalized plastic hinge concepts for 3D beam-column elements", EERC Report No. 82-20, Berkeley: Earthquake Engineering Research Center, University of California, 1982.

[32] C.W. Roeder, and E.P. Popov, "Inelastic behavior of eccentric braced steel frames under cyclic loadings", EERC Report No. 7718, Berkeley: Earthquake Engineering Research Center, University of California, 1977.

[33] M.S. Yang, "Seismic behavior of an eccentrically X-braced steel structure", EERC Report No. 82-14, Berkeley: Earthquake Engineering Research Center, University of California, 1982.

[34] J.M. Ricles, and E.P. Popov, "Inelastic link element for EBF seismic analysis", Journal of Structural Engineering, ASCE, vol. 120, no. 2, pp. 441-63, 1994.

[35] A. Saritas, and F.C. Filippou, "Modeling of shear-yielding members for seismic energy dissipation", Proceedings of 13th WCEE, $13^{\text {th }}$ World Conference on Earthquake Engineering, Paper No. 1799,2004

[36] M. D'Aniello, R. Landolfo, V. Piluso, and G. Rizzano, "Ultimate behavior of steel beams under non-uniform bending", Journal of Constructional Steel Research, vol. 78, pp. 144-158, 2012.
[37] Pacific Earthquake Engineering Research Center, PEER Strong Motion Database, http://peer.berkley.edu.smcat

[38] D. Vamvatsikos, and C.A Cornell, "Incremental Dynamic Analysis", Earthquake Engineering and Structural Dynamics, vol. 31, pp. 491-514, 2002.

[39] N. Luco, and C.A. Cornell, "Seismic drift demand for SMFR structures with brittle connections," Structural Engineering World Wide 1998, Elsevier Science Ltd, Oxford, England Paper T158-3, 1998.

[40] F. Jalayer, and C.A. Cornell, "A technical framework for probability-based demand and capacity factor design (DCFD)" Seismic Formats, PEER Report 2003/06, 2003.

[41] C.A. Cornell, and H. Krawinkler, "Progress and challenges in seismic performance assessment," http://peer.berkeley.edu/news/2000spring/performance/ html.febwetg4wt4, 2000.

[42] A. Longo, R. Montuori, and V. Piluso, "Influence of design criteria on seismic reliability of X-braced frames", Journal of Earthquake Engineering, vol. 12, Issue 3, pp. 406-431, 2008.

[43] V. Piluso, G. Rizzano, and I. Tolone, "Seismic reliability assessment of a two-story steel-concrete composite frame designed according to eurocode 8", Structural Safety, vol. 31, Issue 5, pp. 383$395,2009$.

[44] A. Longo, R. Montuori, and V. Piluso, "Seismic reliability of vbraced frames: influence of design methodologies", Earthquake Engineering and Structural Dynamics, vol. 38, no. 14, pp. 1587$1608,2009$.

[45] A. Longo, R. Montuori, and V. Piluso, "Seismic reliability of chevron braced frames with innovative conception of bracing members", Advanced Steel Construction, vol. 5, no. 4, pp. 367-389, 2009.

[46] M.T. Giugliano, A. Longo, R. Montuori, and V. Piluso, "Seismic reliability of traditional and innovative concentrically braced frames", Earthquake Engineering and Structural Dynamics, vol. 40, no. 13 , pp. $1455-1474$

(c) Mastrandrea et al.; Licensee Bentham Open.

This is an open access article licensed under the terms of the Creative Commons Attribution Non-Commercial License (http://creativecommons.org/licenses/by-nc/3.0/) which permits unrestricted, non-commercial use, distribution and reproduction in any medium, provided the work is properly cited. 